Received: 15 July 2018

Revision received: 19 February 2019

Copyright (C) 2019 ESTP

Accepted: 08 April 2019

www.estp.com.tr

DOI 10.12738/estp.2019.2.004 • April 2019 • 19(2) • 58-73

Article

\title{
Factors Influencing Postgraduate Students' Performance: A high order top down structural equation modelling approach
}

\author{
Noor Ul Hadi \\ Department of Business Administration \\ Foundation University Islamabad, Pakistan
}

\author{
Barudin Muhammad \\ Universiti Kuala Lumpur Business School, \\ Malaysia
}

\begin{abstract}
Given the influx of new courses and programmes, an increase in the number of local and international students, as well as an upsurge in the number of universities in Malaysia, higher education has become a significant sector. Therefore, this study seeks to identify the factors affecting postgraduate research students' performance. For this purpose, we identified and statistically analysed 41 indicators and 112 valid responses using exploratory factor analysis. We found the existence of higher-order factors, which were statistically evaluated and validated using variance-based structural equation modelling. The study found positive and significant relationships between research students' performance and institutional factor, student' personal factor, and supervisor-related factor. Additionally, our results indicated that students' personal factor had a crucial influence on research students' performance, followed by institutional factor, and supervisor-related factor. Thus, the study provides empirical evidence in support of student development theory and social learning theory. In the larger picture, the study offers a comprehensive model for future research.
\end{abstract}

\section{Keywords}

Postgraduate Students' Performance • Supervisor Factor • Student's Personal Factor • Institutional Factor • PLS-SEM

Correspondence to Noor Ul Hadi, PhD, Assistant Professor, Faculty of Business \& Technology, Department of Business Administration, Foundation University Islamabad. Tel.: +92-300-3957833. E-mail address: n_hadi1@yahoo.com

Citation: Hadi, N. U., \& Muhammad, B. (2019). Factors Influencing Postgraduate Students' Performance: A high order top down structural equation modelling approach. Educational Sciences: Theory \& Practice, 19(2), 58-73. http://dx.doi.org/10.12738/estp.2019.2.004 


\section{Background}

Based on research literature, we find that issues in postgraduate research are not limited to developing countries but are also experienced in the developed world (Kearney, 2008), although developed countries are a little ahead in addressing these issues (Minnesota Measures, 2007). In Malaysia, the introduction of new programmes and courses in universities has led to an increase in the number of universities, as well as the number of local and international students every year (Alavi \& Mansor, 2011). According to Meerah (2010), more learners are entering doctoral projects, with countries interested in creating more researchers in order to produce quality human capital. Against this backdrop, this study aims to identify factors that influence postgraduate research students' performance.

Researchers' investigations into the subject have found personal, financial, institutional, supervisorrelated, non-academic, and other factors to be connected to research skills and academic performance (De Zoysa, 2007; Grant, 2005; Meerah, 2010; Wareing, 2009). One of the limitations with this argument is that it does not explain simultaneously to what extent these factors are critical to the performance of postgraduate students nor does they examine which of these factors is of crucial importance. According to Arabaci and Ersozlu (2010), the mentoring skills of supervisors (supervisory factor) have a remarkable influence on postgraduate students' performance. Melissa (2012) affirms that psychological attributes (personal factor) play a key role in postgraduate students' performance. The higher the students' potential for self-efficacy, independent learning, and social support, the greater is their possibility of success. Also, the choice of the institution is crucial for the performance of postgraduate students' performance (MacKeracher, Suart, \& Potter, 2006). Thus, this study intends to further investigate whether and to what extent institutional factor, personal factor, and supervisory factor affect postgraduate research students' performance, and which of these factors is of crucial importance.

The hypothesised relationships of the current study come from student development theory (Astin, 1984) and social learning theory (Bandura, 1977), since environmental influence (institutional factor) and the amount of physical and psychological energy that the research student devotes (student personal factor) to his/her research have a positive effect on his/her performance. We also considered Bandura's (1977) social learning theory since learning is a cognitive process that takes place in a social context and can occur purely through observation or direct instruction (supervisor factor).

\section{Review of Literature}

In general, several researchers have discussed factors influencing the academic performance of students. For instance, Mushtaq and Khan (2012) classify the factors influencing students' performance into two categories: internal classroom factors (fluency in English, teacher performance, technology use in the class, complexity of the course materials, learning facilities, class size, environment of the class), and external classroom factors (financial problems, social problems, family problems, extracurricular activities). Hansen (2000) identify age, gender, and learning facilities as the most crucial factors that affect student performance. Similarly, Al-Mutairi (2011) supports the relationship between personal skills and academic performance. Learning facilities of institutions are found to play a key role in students' performance (Savasci \&Tomul, 2013). Roberts and Sampson (2011) found that qualification of academic staff was critical to student success. Parental education and use of library facilities were found to have an impact on students' academic success (Saenz, Marcoulides, Junn, \& Young, 1999). Kirmani and Siddiquah (2008) found that the academic environment was an effective predictor of students' academic performance. Likewise, Mushtaq and Khan (2012) found a positive correlation between learning facilities and student performance. Proper guidance is also directly proportional to academic performance (Grant \& Graham, 
1994; Mushtaq \& Khan, 2012). The academic performance of postgraduate students will improve if barriers to health (for example, family stress) are low (Mushtaq \& Khan, 2012). Another study conducted by Baharudin, Murad, and Mat (2013) cited a number of studies in the United Kingdom (UK) which have confirmed situational and institutional barriers to be significant.

Several scholars have conducted in-depth studies on factors affecting students' performance at different levels. For example, Crawford and Wang (2016) identified gender and academic achievement for the performance of UK students. Graetz (1995) found that students' educational success depended on their parents' social status. Considine and Zappala (2002) also found parent's social status and income as influential on student achievement. This is concurred by McDonald, Newton, Whetton, and Benefield (2001), who similarly found that parent's socioeconomic conditions (income, academic qualification, and professional qualification) were related to academic performance. Durden and Ellis (1995) cite Staffolani and Bratti's finding that previous high outcomes of students led to their better achievement in the future. However, Huws, Reddy, and Talcott (2006) contradict this, and claim that future academic performance is not determined by past performance. Other studies identify self-motivation, educational background of parents, age, family income, proper guidance, and strong culture as crucial to academic performance in different settings (Ali, Haider, Munir, Khan, \& Ahmed, 2013; Kwesiga, 2002; Meerah, 2010; Williams, 2016). These studies mostly aim to advocate for corrective action in order to advance the academic performance of students.

Ali et al. (2013) found that students in resource-rich schools tended to perform better. Other researchers (e.g., De Zoysa, 2007; Meerah, 2010) found that serious management and availability of funds affected student performance. Higher funding in private schools leads to efficient management, highlymotivated teachers, and access to resources. Those are the key factors to positively affect students' performance. Kwesiga (2002) argues that students' performance is also affected by the school environment.

Specifically, in the context of postgraduate education, Golding, Sharmini, and Lazarovitch (2014) identified examiners' expectations as crucial in the completion of postgraduate studies. Mutula (2009) discussed the challenges faced by postgraduate researchers, and found that these include insufficient research ability, poor supervision, sluggish thesis examination process, declining government financial support, incompatible postgraduate instruction, low throughput, bureaucracy in the admission process, heavy teaching loads, insufficient facilities, balancing occupation and academic work, and poor preparation among postgraduate research students. De Zoysa (2007) found personal, financial, institutional, supervisory, non-academic, and other factors to be the determinants of postgraduate student performance. In her descriptive study, Meerah (2010) found that a lack of research skills negatively affects research students' performance.

We notice, then, much of the literature on the subject is controversial and descriptive in nature, and to our knowledge, there are no multivariate studies that investigate the factors influencing the performance of postgraduate research students in the context of Malaysia. In addition, no research has been found that specifically surveyed postgraduate research students' performance. Thus, it seems imperative to identify the factors crucial in influencing postgraduate research students' performance.

The supervisory factor. Mentoring skills of faculty members at universities have a remarkable impact on the training of postgraduate students. Mentoring skills such as, advising students, to be an exceptional model for them, to transfer knowledge, and to supervise them are key determinants of postgraduate students' performance (Arabaci \& Ersozlu, 2010). Cowan (2006) states that mentoring is a serious topic in the literature on management. Harvey, McIntyre, Heames, and Moeller (2009) mention that traditionally 
mentoring was used for personal, professional, and organisational advice. According to Kay and Hinds (2002, p. 73) "mentoring is a relationship between two independent parties in the management configuration, in which one (mentor) directs the other (mentee) towards an established goal". Mentoring is classified into career supervision and psychosocial supervision (Freedman, 2009). Career supervision consists of behaviours that safeguard the professional success of the mentee. Psychosocial supervision is the personal aspect of the relationship that helps improve the professional identity of the supervisee. The mentor is widely regarded as an effective leader who plays a significant role in the improvement of a junior career within the same organisation (Blickle, Witzki, \& Schneider, 2009; Cowan, 2006; Jessop \& Maleckar, 2016; Maxwell, 2009). A mentor is defined as "a guide, an educator, a leader, and an organiser of the skills that facilitate an individual to recognise their dreams of a perfect life" (Allen \& Eby, 2007, p. 51).

Clutterbuck and Megginson (1999) point out several important characteristics of a mentor - such as the ability to facilitate, support, communicate well, scrutinise, listen well, and to patiently understand the student. Thus, research to date has tended to focus on mentor characteristics in general. To be specific, in the present study, desirable research mentor characteristics are seen as friendliness in research approach, effective research guidance, supporter in research work, dedication to improvement of research skills of the mentee, objective evaluation of mentee research work, regular feedback on mentee research performance, and frequent availability when the mentee (research students') needs him/her.

The quality of supervision also depends on the supervisor's research experience (Affero, Norhasni, $\&$ Aminuddin, 2011). In order to ensure excellence in research supervision, many universities set down requirements that supervisors must meet before they are permitted to oversee student research. For example, the main supervisor must have qualifications equal to or more advanced than that of the students he/she is supervising. Deakin University conducted a Fast-Track Supervisor Training Programme to expedite the process of qualification (Institute of Research Training, 2011). The programme consisted of a series of training workshops and courses aimed at providing knowledge, skills, and practical experience to academic staff in order to improve the execution of their supervisory duties.

Thus, in the present study we operationalise the concept of supervisor experience as a supervisor having the necessary skills and discipline-specific knowledge to adequately support mentee research. A supervisor is considered experienced if he/she provides good guidance in topic selection and modification (if any). A supervisor is experienced if he/she guides the supervisee to publish his/her research work and if he/she provides guidance concerning comprehensive literature review. Several studies have been carried out on mentoring skills and student academic performance, but no single study which examined the role of mentoring skills of supervisor and supervisor experience on research students' performance exists. It is hypothesised that:

H1: There is a relationship between the supervisor factor and postgraduate research students' performance.

The student factors. Besides the quality of a supervisor's mentoring skills and experience, postgraduate students' research performance can also be influenced by their personal characteristics - their competence in learning skills, and their motivation towards the completion of the research project. Astin (1984) points out that the psychic energy that students dedicate to their learning experience is one of the key factors determining their accomplishments in higher education.

Researchers working on learning environments look closely at the role of students' thoughts and beliefs regarding the learning process, and the degree or intensity of their belief in the goals they have established (Dinther, Dochy, \& Segers, 2011; McKenzie \& Schweitzer, 2010). Students with low self- 
efficacy tend to consider responsibilities as more complicated than they actually are; conversely, a higher degree of self-efficacy is associated with a sense of calm.

Bandura (1997) states that self-efficacy plays an important role in human achievement. The four main sources of students' self-efficacy are: enactive mastery experiences, observational experience provided by social models, social influence, and information that people draw from their physiological, emotional, and mood states. Enactive mastery experiences come from real success in dealing with given situations. These experiences of control are the strongest source of efficacy since they provide students with genuine proof that they have the capability to succeed at a task (Palmer, 2006). Students interpret the results of their activities and use those interpretations to develop beliefs about their ability to perform succeeding tasks. Thus, this interpretation creates a sense of self-efficacy. The second source of self-efficacy is created by observational experiences provided by social models (Bandura, 1997). Students receive information about their own skills and capabilities by watching others, particularly those who offer opportunities appropriate for comparison (Schunk, 1987). Social persuasion (influence) is a third source of information that develops student's self-efficacy beliefs. This type of efficacy is most effective when the people who offer this information are viewed by students as competent and reliable, and the information is plausible (Bong \& Skaalvik, 2003). Positive feedback reinforces precursory self-efficacy (Schunk, 1991). The fourth source of information that creates self-efficiency is drawn from peoples' psychological, emotional, and mood states. Emotions such as anxiety, stress, tension, and excitement may be interpreted as signs of incapability and failure. A positive mind-set reinforces the sense of efficacy, while a sad mood negatively affects one's efficacy. Most people rely on this condition in the assessment of their capacity through the perception and interpretation of this information (Pajares, 1997). Because people have the ability to change their own thoughts and feelings, students with a strong sense of self-efficacy are able to visualise a state of tension as an energiser for spectacle. Those who have doubts about their interpretation, see strain as a weakness (Bandura, 1977).

In the present study, we operationalise the concept of student self-efficacy as the ability to solve difficult research-related problems by trying sufficiently hard, the ability to find means and ways to get what one wants, the ease with which one sticks to his/her aims and accomplishes goals, the confidence that one can deal efficiently with unexpected events, the ability to find several solutions when confronted with problems, and the ability to handle things no matter what comes. Therefore, we hypothesise that:

\section{H2: There is a relationship between students' personal characteristics and their performance.}

The institutional factor. For students wishing to pursue postgraduate studies (PS), the choice of the institution is crucial. Wimshurst, Wortley, Bates, and Allard (2006) found that the institutional factor (e.g., the reputable institutions) is the critical factor towards student's academic performance. Also, a research at the University of Botswana found that students were persuaded in favour of certain institutions due to the affordability of fees, the university's reputation, level of financial support offered, diversity of programmes, availability of facilities, availability of qualified staff, and provision of scholarship and research grants. According to MacKeracher et al. (2006), institutional barriers include lack of institutional financial support, the absence of the necessary resources for educational activities, and non-recognition of prior learning credentials.

For purposes of this study, the institutional factor includes: adequate access to necessary research equipment, financial support for research activities, suitable working space for postgraduate research students, provision of computing resources, internet access, adequate library facilities, availability of 
technical support, sound training in research methodologies and econometrics, availability of a good seminar programme for research students, and involvement in a broader research culture.

H3: There is a relationship between the institutional factor and postgraduate research students' performance.

Student performance. Some scholars (Darling, Caldwell, \& Smith, 2005) use Grade Point Average (GPA) to measure student performance. Other scholars take into account previous years' results or test results to measure student performance (Hake, 1998; Hijazi \& Naqvi, 2006). Since our focus is on postgraduate research students, in this study we used subjective measures for postgraduate research students' performance: their level of understanding of research proposal defence/viva, standard of the research project, review of literature, data analysis, interpretation of results, report writing, and monitoring of research project compared to colleagues.

\section{Participants}

\section{Method}

The female participants comprised $29.5 \%(n=33)$ of the sample, and the male participants comprised $70.5 \%(n=79)$. Sixty-eight-point-eight percent of the respondents were single, while $31.2 \%$ were married. Sixty-six respondents were enrolled in a master's degree by research, while 46 were in a doctoral programme by research. Two-point-seven percent respondents were in their first semester of study, followed by $11.6 \%$ in their second semester, $31.3 \%$ in their third semester, $32.1 \%$ in their fourth semester, $17 \%$ in their fifth semester, and the rest were in their sixth semester and above.

\section{Instruments}

Research instruments used in the current study were adapted from relevant studies on the subject (e.g., Abdullah \& Evans, 2011; Arabaci \& Ersozlu, 2010; Hadi \& Muhammad, 2017) and from the operationalised definition of Dinther et al. (2011) and Mutula (2009). Validity of the instruments was ensured via convergent and discriminant validity of the construct. Reliability of the instruments was assessed via Cronbach's alpha and composite reliability. The instruments are considered to be valid and reliable since all values of validity and reliability are above the threshold of .50 and .70. The measurements used in the study are provided in appendix A.

\section{Design and procedure}

Our methodological approach to the current study is quantitative and survey-based. Therefore, cross-sectional quantitative data from 123 postgraduate students enrolled in management programs were conveniently (convenience sampling) collected from four universities [University Kuala Lumpur (UniK), International Islamic University Malaysia (IIUM), University of Malaya (UM), University Technology Malaysia" (UTM)], in the Klang Valley, Malaysia. The sample size was calculated using the software G*Power. To achieve the expected effect size (medium to low, 0.12), with alpha at .05, power at 0.90 , and

the number of predictors equalling $3, G^{*}$ Power proposed the required sample size to be 123 . After getting ethics approval, data collection was started. Prior to study, full consent from participants were obtained. The study also ensured the privacy of research participants. For this purpose, their identities were protected from disclosure and remained unknown. Furthermore, anonymity of each participant in this research has ensured. A required assessment for suspicious responses, missing data, outliers, normality, and collinearity brought down the number of valid responses to 112 . 


\section{Data analysis}

The valid responses were subsequently analysed using SPSS. Hypothetical relationships were predicted via structural equation modelling (SEM) with the application of SmartPLS 3. Since some of the instruments used in this study were modified in the specific context of Malaysia, we used the two-stage approach to validate the model. We first conducted an exploratory factor analysis (EFA), with Principal Component Analysis (PCA) and oblique (oblimin) rotation method (for details, see Hadi, Abdullah, \& Sentosa, 2016a). The appropriateness of the data was assessed via Kaiser Meyer-Olkin (KMO) and Bartlett's test of sphericity. The EFA indicated a certain number of underlying sub-components to each construct. Therefore, to confirm these first-order factors as dimensions of higher-order factor, the Confirmatory Factor Analysis (CFA) was carried out. We used SmartPLS 3.0 to employ the PLS-SEM technique to analyse data. PLS allows the estimation of data from a comparatively small sample (Chin, 1998). Since our sample size seemed to be small, we analysed data via PLS-SEM.

\section{Results}

Table 1 summarises the EFA results. The 14 items on the Supervisory Factor Scale were subjected to principal component analysis (PCA). PCA was chosen due to its prevalent use in business research (Hair, Black, Babin, Anderson, \& Tatham, 2006). The KMO value was .83 points above the suggested minimum value of .50 (Kaiser, 1974). Bartlett's test of sphericity for the supervisory factor scale was statistically significant. Based on eigenvalue, two factors were extracted. The dimensions of the supervisor factor were labelled as Mentoring Skill (as proposed by Arabaci \& Ersozlu, 2010), and the Supervisor Experience (as proposed by Al-Mutairi (2011). It was found that all items converged on the same factors. It was also found that the loading of items on other factors was below the threshold of 0.50 - thereby ensuring construct validity.

The KMO value of .80 indicated that the 10 items on the Student Factor Scale were appropriate for factor analysis. This was supported by Bartlett's test of sphericity by indicating a strong correlation among the items. Two factors were retained for further investigation. The dimensions of student factor were labelled as Self-efficacy (as proposed by Dinther et al., 2011), and Self-motivation (as proposed by Abdullah \& Evans, 2012). The pattern of correlation showed that the four items of self-motivation and five items of selfefficacy were related to their respective constructs. Therefore, all the items converge on their respective constructs. Item 10 was deleted due to low item loading.

Table 1. Test for suitability of data for independent variables

\begin{tabular}{llccc}
\hline & & Supervisor factor & Institutional factor & Student personal factor \\
\cline { 2 - 5 } \multicolumn{2}{c}{ Kaiser Meyer-Olkin } & .83 & .81 & .80 \\
\hline Bartlett's test of sphericity & Aprox. & 450.188 & 381.971 & 337.384 \\
& Chi-Square & & & 36 \\
& Df & 55 & 36 & 36 \\
\hline
\end{tabular}

$p<.001$

The 10 items on the Institutional Factor Scale were subjected to PCA. The KMO value was .81, above the suggested minimum value. Bartlett's test of sphericity for the institutional factor was statistically significant. Based on eigenvalue, two factors were retained for further investigation. The dimensions of institutional factor were labelled as Institutional Infrastructure and Institutional Intellectual Climate (as proposed by Abdullah \& Evans, 2012; Baharudin et al., 2013). Item 4 was taken out due to low loading. To summarise, the instruments used for the institutional factor scale possessed construct validity. 
Table 2. Re-specified Measurement Model Details for the Supervisor Factor, Institutional Factor, and Student Factor.

\begin{tabular}{|c|c|c|c|c|}
\hline Sub-constructs & Standardised factor loading & Cronbach Alpha & $\mathrm{CR}$ & AVE \\
\hline \multicolumn{5}{|l|}{ Supervisor Factor } \\
\hline \multicolumn{5}{|l|}{ Mentoring skills } \\
\hline MS2 & .68 & \multirow{6}{*}{.85} & \multirow{6}{*}{.89} & \multirow{6}{*}{.58} \\
\hline MS3 & .75 & & & \\
\hline MS5 & .71 & & & \\
\hline MS7 & .71 & & & \\
\hline MS8 & .87 & & & \\
\hline MS9 & .82 & & & \\
\hline \multicolumn{5}{|l|}{ Experience } \\
\hline SE11 & .77 & \multirow{4}{*}{.69} & \multirow{4}{*}{.83} & \multirow{4}{*}{.62} \\
\hline SE12 & .73 & & & \\
\hline SE13 & .81 & & & \\
\hline SE14 & Removed & & & \\
\hline \multicolumn{5}{|l|}{ Institutional Factor } \\
\hline \multicolumn{5}{|l|}{ Infrastructure } \\
\hline INFRA1 & .81 & \multirow{5}{*}{.75} & \multirow{5}{*}{.85} & \multirow{5}{*}{.66} \\
\hline INFRA2 & Removed & & & \\
\hline INFRA3 & .80 & & & \\
\hline INFRA5 & .82 & & & \\
\hline INFRA6 & Removed & & & \\
\hline \multicolumn{5}{|l|}{ Intellectual climate } \\
\hline INT7 & .86 & \multirow{4}{*}{.87} & \multirow{4}{*}{.91} & \multirow{4}{*}{.72} \\
\hline INT8 & .85 & & & \\
\hline INT9 & .89 & & & \\
\hline INT10 & .79 & & & \\
\hline \multicolumn{5}{|l|}{ Student Factor } \\
\hline \multicolumn{5}{|l|}{ Attitude towards research } \\
\hline SAT1 & .86 & \multirow{4}{*}{.72} & \multirow{4}{*}{.84} & \multirow{4}{*}{.64} \\
\hline SAT2 & Removed & & & \\
\hline SAT3 & .77 & & & \\
\hline SAT4 & .76 & & & \\
\hline \multicolumn{5}{|l|}{ Self-efficacy } \\
\hline SEF5 & .79 & \multirow{5}{*}{.85} & \multirow{5}{*}{.90} & \multirow{5}{*}{.69} \\
\hline SEF6 & .84 & & & \\
\hline SEF7 & .82 & & & \\
\hline SEF8 & .85 & & & \\
\hline SEF9 & Removed & & & \\
\hline
\end{tabular}

Note. $\mathrm{CR}=$ Composite Reliability; AVE = Average Variance Extracted

\section{Assessment of the Measurement Models}

The measurement model for all exogenous constructs was validated by evaluating construct reliability and construct validity as proposed by Hadi et al. (2016b), and Henseler, Ringle, and Sinkovics (2009). Internal consistency of the constructs was evaluated by their composite reliability (CR). All composite reliability values were found to be above the threshold of .70, ranging from .83 to .91 (Table 2). Thus, all constructs confirmed internal consistency. We measured convergent validity by average variance extracted (AVE) values for each construct, as proposed by Fornell and Larcker (1981). According to the Fornell and Larcker criterion, convergent validity is ensured if the value of AVE is above .50. Our results 
revealed that the variance extracted for the three scales ranged from .58 to .72 . This shows that the scales used for each factor used possessed convergent validity.

The quality of the measurement model was further assessed via both convergent and discriminant validity. Convergent validity (CV) was verified via item loadings and AVE. Table 2 shows that all valid item loadings were higher than .50, indicating that all constructs had the ability to explain more than $50 \%$ of the variance of their items on average. Therefore, convergent validity was ensured.

\section{Discriminant Validity}

Discriminant validity for all exogenous constructs was evaluated by the test suggested by Fornell and Larcker (1981), in which one compares whether AVE is higher than the square of correlations among the constructs in the model. Table 3 shows that all diagonal values (the square root of the AVE) exceeded inter-construct correlations, ensuring discriminant validity.

Table 3. Discriminant Validity (Fornell-Larcker Criterion)

\begin{tabular}{lcccc}
\hline Construct & $\begin{array}{c}\text { Institutional } \\
\text { factor }\end{array}$ & $\begin{array}{c}\text { Postgraduate Students' } \\
\text { Performance }\end{array}$ & $\begin{array}{c}\text { Students } \\
\text { factor }\end{array}$ & $\begin{array}{c}\text { Supervisor } \\
\text { factor }\end{array}$ \\
\hline Institutional factor & .70 & - & & \\
Postgraduate Students Performance & .31 & .71 & - & \\
Students factor & .08 & .35 & .65 & - \\
Supervisor factor & .17 & .31 & .14 & .66 \\
\hline
\end{tabular}

\section{Structural Model}

After establishing the fitness of the measurement models, the next phase is to provide evidence which supports the theoretical model (structural model). In PLS-SEM, the structural model and hypotheses are tested via path coefficients. To know how well the data fit the model, the coefficient of determination $\left(R^{2}\right)$ for endogenous construct was considered as proposed by Chin (1998). We also considered the predictive relevance $\left(\mathrm{Q}^{2}\right)$ and $f$ efffect size.

Figure 1 shows the results of the structural model. The $R^{2}$ value of postgraduate research students' performance is $25.8 \%$. As mentioned earlier, the structural model and hypotheses are tested by computing path coefficients, i.e., $\beta$. The relationship between the supervisory factor and students' performance was significant with $\beta=0.23, t=2.24$, with a $p$-value of .02 , representing that the supervisory-factor has a direct, positive, and significant influence on postgraduate students' performance (see Table 4 for details). The association between the institutional factor and postgraduate students' performance was significant, with $\beta=$ $0.24, t=2.58$, and $p=.01$. This indicates that the institutional factor has a direct, positive, and significant influence on postgraduate students' performance. The relationship between the student factor and student performance was also statistically significant, with $\beta=0.30, t=2.86$, and $p=.00$, implying that the postgraduate research students' performance changes in direct proportion to the student personal factor.

All dimensions were confirmed as belonging to the respective independent variables. The independent variables together explained $25.8 \%$ of the variance in the dependent variable. Among these, the student personal factor was found to be the most influential $(t=2.86)$, followed by the institutional factor $(t=2.58)$, and the supervisory factor $(t=2.24)$. Results also indicate that the model is highly predictive, as the value of predictive relevance $\left(\mathrm{Q}^{2}\right)$ is above the threshold of zero (Chin, 1988). It was further found that the effect size of student personal factor on postgraduate research student performance ( $R^{2}$ value) is comparatively large and above the threshold of .35 . 


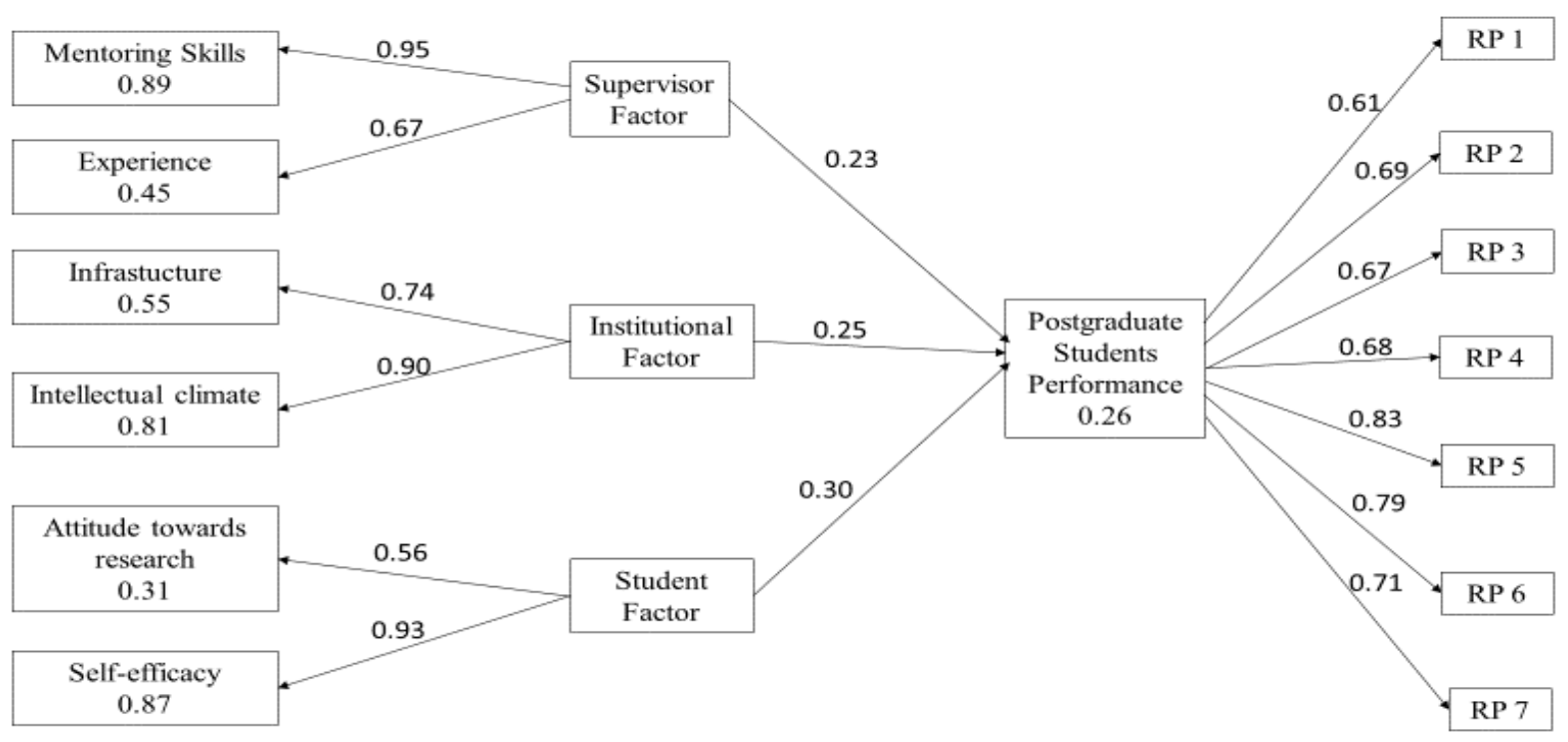

Figure 1. Structural model with path coefficients

Table 4. Path Coefficients, $t$ value and $p$ values

\begin{tabular}{llccc}
\hline \multicolumn{1}{c}{ Path } & $\beta$ & Standard Error & $\begin{array}{c}t \\
\text { values }\end{array}$ & $\begin{array}{c}p \\
\text { values }\end{array}$ \\
\hline Institutional factor $\rightarrow$ Infrastructure & .74 & 0.05 & 14.10 & .000 \\
Institutional factor $\rightarrow$ Intellectual Capital & .90 & 0.02 & 45.13 & .000 \\
Institutional factor $\rightarrow$ Postgraduate students' performance & .24 & 0.09 & 2.58 & .010 \\
Students factor $\rightarrow$ Attitude towards' research & .55 & 0.14 & 3.92 & .000 \\
Students factor $\rightarrow$ Postgraduate Students' Performance & .30 & 0.10 & 2.86 & .004 \\
Student factor $\rightarrow$ Self-efficacy & .93 & 0.02 & 32.14 & .000 \\
Supervisor factor $\rightarrow$ Experience & .67 & 0.07 & 9.40 & .000 \\
Supervisor factor $\rightarrow$ Mentoring skills & .94 & 0.01 & 91.52 & .000 \\
Supervisor factor $\rightarrow$ Postgraduate Students Performance & .23 & 0.10 & 2.24 & .025 \\
\hline
\end{tabular}

\section{Discussion}

The purpose of this study was to identify the factors crucial in influencing the performance of postgraduate research students. The relationship between supervisor performance and postgraduate student performance is statistically significant implying that the supervisor factor affects postgraduate student performance. This finding is in line with past studies (such as Affero et al., 2011; Arabaci \& Ersozlu, 2010; Grant, 2003; Hadi \& Muhammad, 2017). However, much of these studies are descriptive in nature. More specifically, the key problem with Hadi and Muhammad explanation is that they overlook the explanatory power of other relevant variables in their study. The study also contributes additional evidence that suggests that the role of the supervisory factor in the performance of postgraduate research students' is critical, indicating that the link between supervisor factor and postgraduate research student performance supposed philosophically by the social learning theory was supported by our data set. 
The analysis of the direct path student personal factor to postgraduate research students' performance indicates that student personal factor has a positive and statistically significant influence on postgraduate research students' performance. As such, the higher the degree or intensity of a student's dedication to his/her research, the better their research performance (student development theory) is. This finding is also in line with the prior studies which point out that the psychic energy that students dedicate to their learning experience is a crucial factor influencing students' success (Astin, 1984; Dinther et al., 2011; McKenzie \& Schweitzer, 2010). These findings make a good contribution to the current literature on postgraduate research students' performance as, the more capable and confident the postgraduate research students are, the more they will be able to conduct their research independently.

The path from institutional factor to student performance is statistically significant, indicating that the performance of postgraduate research students varies in direct proportion to institutional factors. A change in one unit on the standardised factor scores of the institutional factor corresponds to a change of a unit in the standardised postgraduate research students' performance scores. This finding supports the past studies by MacKeracher et al. (2006), Mushtaq and Khan (2012), and Li (2018) who conjecture that resources necessary for educational activities (environmental influence) and other learning facilities are critical for postgraduate research students' performance.

\section{Policy implications}

The results lead to several implications. First, in relation to the policy implication, higher education policy makers and administrators must consider the positive and significant role of institutional and supervisory factor because our results provide empirical evidence on the applicability of Bandura's social learning theory in the context of Malaysia. Therefore, we posit that the cognitive ability of postgraduates' students can be positively affected by these two factors which then affect their research performance. Second, regarding their theoretical implications, the outcomes of this study have contributed to the advancement of theory and understanding of higher education in the Malaysian context.

Findings of the study are also important for postgraduate research students, postgraduate research supervisors and academic institutions. For the successful completion of research in specified time, postgraduate research students have to depend more on their academic self-efficacy. In relation to research supervisors, they have to make adequate use of their mentoring skill, and to encourage research student's self-efficacy. Academic institutions can recognize the importance of strong research culture for postgraduate research students' performance. Finally, the study concluded from the findings that the physical and psychological energy of research students positively affects their research performance.

\section{Limitations and potential for future research}

Our study provides four main limitations that provide potential directions for future research. The main limitation of this study is its small sample size and convenient sampling method, even though 123 participants are satisfactory for power analysis and PLS-SEM (Hair, Hult, Ringle, \& Sarstedt, 2014). Additionally, we only considered a cross-sectional approach. Future research needs to investigate possible two-way effects. Further, whereas we only considered direct effects, it would be more meaningful to consider the effect of intervening variables in different settings. Also, this study considered three independent variables (student factor, institutional factor, and supervisory factor) which explained only about $26 \%$ of the variance. Even there is no absolute value for $R^{2}$, typically is higher in time-series regressions than in cross-section regressions (Halcoussis, 2005). Finally, it is strongly suggested to consider the moderating and mediating role of other variables in future studies. 


\section{References}

Abdullah, M. Y., \& Evans, T. (2012). The relationships between postgraduate research students' psychological attributes and their supervisors' supervision training. Procedia - Social and Behavioural Sciences, 31, 788793. https://doi.org/10.1016/j.sbspro.2011.12.142

Affero, I., Norhasni, Z. A., \& Aminuddin, H. (2011). Improving the development of postgraduate's research and supervision. International Education Studies, 4, 78-90. doi:10.5539/ies.v4n1p78

Alavi, M., \& Mansor, S. M. S. (2011). Categories of problems among international students in University Technology Malaysia. Procedia - Social and Behavioural Sciences, 30, 1581-1587. doi: 10.1016/j.sbspro.2011.10.307

Ali, S., Haider, Z., Munir, F., Khan, H., \& Ahmed, A. (2013). Factors contributing to the students' academic performance: A case study of Islamia University sub-campus. American Journal of Educational Research, 1, 283-289. doi: 10.12691/education-1-8-3.

Allen, T., \& Eby, L. (2007). The Blackwell handbook of mentoring: A multiple perspective approach. Malden, MA: Blackwell. doi:10.1111/b.9781405133739.2007.x

Al-Mutairi, A. (2011). Factors affecting business students' performance in Arab Open University: The case of Kuwait. International Journal of Business and Management, 6, 146-155. doi: 10.5539/ijbm.v6n5p146

Arabacı, İ. B., \& Ersözlü, A. (2010). Postgraduate students' perceptions of their supervisors' mentoring skills. Procedia - Social and Behavioural Sciences, 2, 4234-4238. https://doi.org/10.1016/j.sbspro.2010.03.670

Astin, A. W. (1984). Student involvement: A developmental theory for higher education. Journal of College Student Personnel, 25, 297-308.

Australian Graduate Survey. (2009). Postgraduates: Summary Report. Planning Unit: Deakin University.

Baharudin, S. N. A., Murad, M., \& Mat, N. H. H. (2013). Challenges of adult learners: A case study of full-time postgraduates' students. Procedia - Social and Behavioural Sciences, 90, 772-781.

Bandura, A. (1997). Self-efficacy: The exercise of control. New York: W.H. Freeman and Company.

Bandura, A. (1977). Social learning theory. New York: General Learning Press.

Bartlett, M. S. (1954). A note on the multiplying factors for various chi square approximation. Journal of Royal Statistical Society, 16, 296-308.

Blass, E., Jasman, A., \& Shelley, S. (2012). Postgraduate research students: You are the future of the academy. Futures, 44, 166-173. https://doi.org/10.1016/j.futures.2011.09.009

Blickle, G., Witzki, A. H., \& Schneider, P. B. (2009). Mentoring support and power: A three-year predictive field study on protégé networking and career success. Journal of Vocational Behaviour, 74, 181-189. http://dx.doi.org/10.1016/j.jvb.2008.12.008

Bong, M., \& Skaalvik, E. M. (2003). Academic self-concept and self-efficacy: How different are they really? Educational Psychology Review, 15, 1-40. http://dx.doi.org/10.1023/A:1021302408382

Chin, W. W. (1998). The partial least squares approach for structural equation modelling. In G. A. Marcoulides (Ed.), Modern Methods for Business Research (pp. 295-336). Manwah, NJ: Lawrence Erlbaum Associates.

Clutterbuck, D., \& Megginson, D. (1999). Mentoring executives and directors. Oxford: Butterworth-Heinemann.

Considine, G., \& Zappala, G. (2002). Influence of social and economic disadvantage in the academic performance of school students in Australia. Journal of Sociology, 38, 129-148. https://doi.org/10.1177/1440783021287565 43.

Cowan, S. L. (2006). So You Want to Be Mentored: An Application Workbook for Using Five Strategies to Get the Most out of a Mentoring Relationship. Amherst: HRD Press, Inc.

Crawford, I., \& Wang, Z. (2016). The Impact of placements on the academic performance of UK and international students in higher education. Studies in Higher Education, 41, 712-733. https://doi.org/10.1080/03075079. 2014.943658

Darling, N., Caldwell, L. L., \& Smith, R. (2005). Participation in School-Based Extracurricular Activities and Adolescent Adjustment. Journal of Leisure Research, 37, 51-76.

De Zoysa, T. S. V. (2007). Factors affecting the completion of post graduate degree using distance mode. http:///wikieducator.org/images/a/a0/PID_383.pdf

Dinther, M., Dochy, F., \& Segers, M. (2011). Factors affecting students' self-efficacy in higher education. Educational Research Review, 6, 95-108. http://dx.doi.org/10.1016/j.edurev.2010.10.003

Durden, G. C., \& Ellis, L. V. (1995). The effect of attendance on student learning in Principles of Economics. American Economic Review, 85, 343-346.

Fornell, C., \& Bookstein, F. L. (1982). Two structural equation models: LISREL and PLS applied to consumer exitvoice theory. Journal of Marketing Research, 19, 440-452. 
Fornell, C., \& Larcker, D. F. (1981). Evaluating structural equation models with unobservable variables and measurement error. Journal of Marketing Research, 18, 39-50.

Freedman, S. (2009). Effective mentoring. IFLA Journal, 35, 171-182. https://doi.org/10.1177/0340035209105672

Golding, C., Sharmini, S., \& Lazarovitch, A. (2014) What examiners do: What thesis students should know. Assessment \& Evaluation in Higher Education, 39, 563-576. https://doi.org/10.1080/02602938.2013.859230

Graetz, B. (1995). Socio-economic status in education research and policy. In John Ainley et al. Socio-economic Status and School Education. Canberra: DEET/ACER

Grant, B. M. (2005). The pedagogy of graduate supervision: Figuring the relations between supervisor and student. $\mathrm{PhD}$ thesis submitted to the University of Auckland, Aotearoa, New Zealand.

Grant, B. M. (2003). Mapping the pleasures and risks of supervision. Discourse: Studies in the Cultural Politics of Education, 24, 173-188. https://doi.org/10.1080/01596300303042

Grant, B. M., \& Graham, A. (1994). "Guidelines for discussion": A tool for managing postgraduate supervision. In O. Zuber-Skerritt \& Y. Ryan (Eds.), Quality in Postgraduate Education (pp. 165-177). London: Kogan Page.

Hadi, N. U., Abdullah, N., \& Sentosa, I. (2016a). An easy approach to exploratory factor analysis: Marketing perspective. Journal of Educational and Social Research, 6, 215-223. doi: 10.5901/jesr. 2016.v6n1p215

Hadi, N. U., Abdullah, N., \& Sentosa, I. (2016b). Making sense of mediating analysis: a marketing perspective. Review of Integrative Business and Economic Research, 5, 62-76.

Hadi, N. U., \& Muhammad, B. (2017). Role of supervisor in the performance of postgraduate research students. Journal of Research and Reflections in Education, 11, 178-186.

Hair, J. F., Black, W. C., Babin, B. J., Anderson, R. E., \& Tatham, R. L. (2006). Multivariate data analysis (6th Ed.). Upper Saddle River: Pearson Education International.

Hair, J. F., Hult, G. T. M., Ringle, C. M., \& Sarstedt, M. (2014). A Primer on Partial Least Squares Structural Equation Modeling. Thousand Oaks: Sage.

Hake, R. (1998). Interactive-engagement vs. traditional engagement "A six-thousand-student survey of mechanics test data for Introductory Physics courses. American Journal of Physics, 66, 64-74. doi: 10.1119/1.18809

Halcoussis, D. (2005). Understanding econometrics. Mason, OH: South-Western/Thomson.

Hansen, J. B. (April 2000). Student Performance and Student Growth as measure of success: A evaluator's perspective. Paper presented at Annual Meeting of the American Educational Research Association. New Orleans, Louisiana, April 25, 2000

Harvey, M., McIntyre, N., Heames, J. T., \& Moeller, M. (2009). Mentoring global female managers in the global marketplace: Traditional, reverse, and reciprocal mentoring. The International Journal of Human Resource Management, 20, 1344 - 1361. https://doi.org/10.1080/09585190902909863

Henseler, J., Ringle, C. M., \& Sinkovics, R. R. (2009). The use of partial least squares path modelling in international marketing. Advances in International Marketing, 20, 277-320. https://doi.org/10.1108/S1474-7979(2009)000 0020014

Hijazi, S. T., \& Naqvi, S. M. M. R. (2006). Factors affecting students' performance: A case of private colleges. Bangladesh e-Journal of Sociology, 3, 1- 10.

Huws, N., Reddy, P., \& Talcott, J. (2006). Predicting University Success in Psychology: Are Subject-Specific Skills Important? Psychology Learning \& Teaching, 5, 133-140. https://doi.org/10.2304/plat.2005.5.2.133

Institute of Research Training. (2011). Fast-track supervisor training program. Retrieved September 2011 from http://www.deakin.edu.au/research/admin/ecr/documents/fast-track-program.pdf

Jessop, T., \& Maleckar, B. (2016). The influence of disciplinary assessment patterns on student learning: a comparative study. Studies in Higher Education, 41, 696-711. https://doi.org/10.1080/03075079.2014.943170

Kaiser, H. (1974). An index of factorial simplicity. Psychometrika, 39, 31-36. https://doi.org/10.1007/BF02291575

Kay, D., \& Hinds, R. (2002). A practical guide to mentoring: Play and active and worthwhile part in the development others and improve your own skills in the process. Oxford, UK: How to Books.

Kearney, M. L. (2008). The role of postgraduate education in research systems. Proceedings of UNESCO/DCU Workshop on Trends in Post -Graduate education, 5-7 March 2008, Dublin City, Ireland.

Kirmani, N. S., \& Siddiquah, A. (December 2008). Identification and Analysis of Factors Affecting Students Achievement in Higher Education. 2nd International Conference on Assessing Quality in Higher Education, 424-437.

Kwesiga, C. J. (2002). Women's access to higher education in Africa: Uganda's experience. Kampala: Fountain publishers Ltd.

Li, N. (2018). Research on the correlation between law teaching reform and students' academic performance based on regression analysis method. Educational Sciences: Theory \& Practice, 18, 1620-1627. doi: 10.12738/estp. 2018.5.061 
MacKeracher, D., Suart, T., \& Potter, J. (2006). State of the field report: Barriers to participation in adult learning. [Online Article]. Retrieved on Nov, 2014 from http://www.nald.ca/library/research/sotfr/barriers/ barriers.pdf

Maxwell, G. (2009). "Mentoring for enhancing females' career development: the bank job". Equal Opportunities International, 28, 561-576. https://doi.org/10.1108/02610150910996407

McDonald, A. S., Newton, P. E., Whetton, C., \& Benefield, P. (2001). Aptitude testing for University entrance: A literature review. Slough: National foundation for educational research in England and Wales.

McKenzie, K., \& Schweitzer, R. (2010). Who succeeds at University? Factors predicting academic performance in first year Australian university students. Higher Education Research \& Development, 20, 21-33. https://doi.org/10.1080/ 07924360120043621

Meerah, T. S. M. (2010). Readiness of preparing postgraduate students in pursuit of their doctoral programme. Procedia Social and Behavioural Sciences, 9, 184-188. https://doi.org/10.1016/j.sbspro.2010.12.133

Melissa. (2012, September 19). Holding High Expectations. Retrieved from: https://www.aaeteachers.org/index.php/ blog/838-holding-high-expectations.

Minnesota Measures. (2007). Report on higher education performance. Retrieved on Dec, 2014 from www.opencongress. org/bill/110.s/642/show-139k.

Mushtaq, I., \& Khan, S. N. (2012). Factors affecting students' academic performance. Global Journal of Management and Business Research, 12, 16-22.

Mutula, S. M. (2009). Challenges of postgraduate research: Global context, African perspectives. Key note address delivered at the University of Zululand, 10th DLIS Annual Conference, from 9-10 (September 2009), 1-13.

Pajares, F. (1997). Current directions in self-efficacy research. In M. Maehr, \& P. R. Pintrich (Eds.), Advances in motivation and achievement (pp. 1-49). Greenwich: JAI Press.

Palmer, D. H. (2006). Sources of self-efficacy in a science methods course for primary teacher education students. Research in Science Education, 36, 337-353. https://doi.org/10.1007/s11165-005-9007-0

Roberts, K. L., \& Sampson, P. M. (2011). School board member professional development and effect on student achievement. International Journal of Educational Management, 25, 701-713. http://dx.doi.org/10.1108/ 095 13541111172108

Saenz, T., Marcoulides, G. A., Junn, E., \& Young, R. (1999). The relationship between college experience and academic performance among minority student. International Journal of Educational Management,13, 199207. https://doi.org/10.1108/09513549910278124

Savasci, H. S., \& Tomul, E. (2013). The Relationship between educational resources of School and academic achievement. International Education Studies, 6, 114-123. doi: 10.5539/ies.v6n4p114

Schunk, D. H. (1991). Self-efficacy and academic motivation. Educational Psychologist, 26, 207-231. http://dx. doi.org /10. 1207/s15326985ep2603\&4_2

Schunk, D. H. (1987). Peer models and children's behavioural change. Review of Educational Research, 57, 149-174. https://doi.org/10.3102/00346543057002149

Wareing, S. (2009). Disciplines, discourse and orientalism: The implications for postgraduate certificates in learning and teaching in higher education. Studies in Higher Education, 34, 917-928. https://doi.org/10.1080/ 03075070902929519

Williams, J. (2016). A critical exploration of changing definitions of public good in relation to higher education. Studies in Higher Education, 41, 619-630. https://doi.org/10.1080/03075079.2014.942270

Wimshurst, K., Wortley, R., Bates, M., \& Allard, T. (2006). The impact of institutional factors on student academic results: implications for 'quality' in universities. Higher Education Research \& Development, 25,131145. doi: 10.1080/07294360600610370 


\section{Appendix A}

\section{Survey questionnaires}

\section{Supervisor factor}

\section{Mentoring skills}

MS2 "My supervisor is my greatest supporter in my work"

MS3 "My supervisor spends a lot of effort to help me improve academically"

MS5 "My supervisor adopts a friendly approach toward me"

MS7 "My supervisor leads the way from me to benefit from opportunities"

MS8 "My supervisor regularly gives feedback on my performance"

MS9 "My supervisor provides positive and constructive criticism"

Experience

SE11 "My supervisor has the skills and necessary subject knowledge to adequately support my research"

SE12 "I have been given good guidance in topic selection and refinement by my supervisor"

SE13 "I have received good guidance in my literature search from my supervisor"

\section{Institutional factor}

\section{Infrastructure}

INFRA1 "I have adequate access to the equipment necessary for my research"

INFRA2 "I have a suitable working space at my campus"

INFRA3 "There is appropriate financial support for research activities"

INFRA5 "There is adequate provision of library facilities"

INFRA6 "I have the technical support I need"

Intellectual climate

INT7 "My department provides opportunities necessary for my research"

INT8 "My department provides opportunities for me to become involved in the broader research culture"

INT9 "The research ambience in my faculty stimulates my work"

INT10 "My department provides symposium and seminar programs"

\section{Student factor}

Attitude towards research

SAT1 "I hesitate on taking time away from study"

SAT2 "I often think about my study when I am away from home"

SAT3 "I always try to obtain feedback on my performance from my seniors and colleagues"

SAT4 "When I am unable to understand a relevant topic I stay patiently and try to get it rather to give up"

Self-efficacy

SEF5 "I can always manage to solve difficult problems if try hard enough"

SEF6 "If someone opposes me, I can find means and ways to get what I want"

SEF7 "It is easy for me to stick to my aims and accomplish my goals"

SEF8 "I am confident that I could deal efficiently with unexpected events"

SEF9 "When I am confronted with a problem, I can usually find several solutions"

Anchored by: Strongly disagree (1) to Strongly Agree (5). 


\section{Postgraduates research students' performance}

In your research program, how well you are treating yourself compared with your colleagues in term of the following criteria.

RP1 Monitoring research project

RP2 Commitment

RP3 Work quality

RP4 Problem definition

RP5 Research methodology

RP6 Write-up

RP7 Publication

Anchored by: Poor (1) to Excellent (5). 